\title{
Structural Settlement Analysis and Pre-Reinforcement Research by Considering Structure Stiffness
}

\author{
Shaodong YUAN, Guangming YU, Liang LI*
}

\begin{abstract}
The movement of the ground caused by the excavation of subway tunnels and the sinking of the earth's surface inevitably affect above-ground buildings, with the impact on historical and cultural buildings, which are already in disrepair, being more prominent. In existing research, the impact of the stiffness of a building itself is often neglected when assessing the influence of the displacement of the stratum caused by tunnel excavation on the building. However, as the settlement and deformation of the building are related to the structural characteristics of the building itself, the effect of the building stiffness should not be completely ignored. This study analyzed the case of the national key protected cultural relics (Red House Hotel) located near the tunnel of the Qingdao Metro (Line 3). Based on the factors affecting the stiffness of the building structure, the Peck empirical formula was modified to predict the effect on the building in the stratum. Subsequently, a three-dimensional finite element model was established and force analysis conducted. Considering the results of the finite element analysis, which determined the stress condition of the cultural relic buildings, a reinforcement design was carried out and implemented in the project.
\end{abstract}

Keywords: analysis; reinforcement design; stiffness of the building structure; tunnel excavation

\section{INTRODUCTION}

Subways in urban areas have become an effective means of reducing traffic congestion. However, tunnel excavation for a subway causes movement of the stratum and sinking of the surface [1], as the buildings are usually dense and subway routes are mostly placed in the prosperous sections of a city. Therefore, research [2-5] on protection and reinforcement technology for the buildings under which a subway passes has become a necessary branch of subway construction.

In existing research, the impact of the stiffness of a building itself is often neglected when assessing the influence of the displacement of the stratum caused by tunnel excavation on the building. The settlement and deformation of the building are related to the structural characteristics of the building itself; therefore, the effect of the building stiffness should not be completely ignored. Based on the factors influencing the stiffness of building structures, this paper corrects the conventional empirical formula (Peck formula) [6] for calculating surface deformation. Furthermore, using the Red House Hotel historical building near the subway tunnel of the Qingdao Metro Line 3 project as a case study, the effect of tunnel excavation on the construction and reinforcement of historical buildings is analyzed.

\section{PROJECT OVERVIEW}

With a total length of $24.9 \mathrm{~km}$, the Qingdao Metro Line 3 project (the object) is located at No. 33, Guangxi Road (the Qingren section of Metro Line 3 passes through it) and the Red House Hotel is one of the buildings located near the subway tunnel.

\subsection{Building Overview}

The Red House Hotel, which used to be a pharmacy, is located at No. 33 Guangxi Road, Qingdao. It was built in 1905 and refurbished in 1949. Designed by the German architect Kurt Rothkegel, it is a typical German building and is recognized as a cultural relic protected at the national level. This building was first used as a German medical store, and is currently used as a commercial hotel.

\subsection{Structural Overview}

With an area of approximately $1939.69 \mathrm{~m} 2$ and a height of approximately $14.07 \mathrm{~m}$, the building holds a masonry structure with three floors above the ground and one floor underground. The exterior wall of the lower part of the building is constructed with granite blocks, and granite pillars stand in the lobby of the first floor. In addition, the brick wall enjoys great bearing capacities: the thickness of the exterior wall is $600 \mathrm{~mm}$ while the interior wall is $400 \mathrm{~mm}$ thick. At first, the plank was used as the building slab, and the mesh reinforcement was added under the plank after the renovation. The roof is featured by a truss with a timber structure. The plane and space relationships between the Red House Hotel and subway tunnel are shown in Fig. 1.

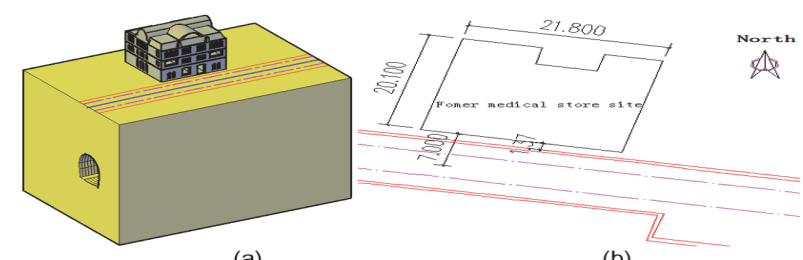

Figure 1 (a) Spatial positional relationship and (b) relationship of plan position

\section{SURFACE AND BUILDING SETTLEMENTS CAUSED BY TUNNEL EXCAVATION}

\subsection{Lateral Settlement of Surface}

When the stratum is a homogeneous layer, the lateral settlement caused by tunnel excavation can be calculated according to the Peck empirical formula, as follows:

$S(y)=S_{\max } \exp \left(-\frac{y^{2}}{2 i_{y}^{2}}\right)$

In this formula, $y$ represents the horizontal distance from the ground point corresponding to the centerline of 
the tunnel to the calculated point; $S_{\max }$ represents the settlement value at the symmetry point of the curve; $i_{y}$ represents the horizontal distance from the ground point, corresponding to the centerline of the tunnel, to the inflection point of the settlement curve. The cross-sectional curve of the settling tank generally follows the normal distribution (Gaussian distribution) law, as shown in Fig. 2.

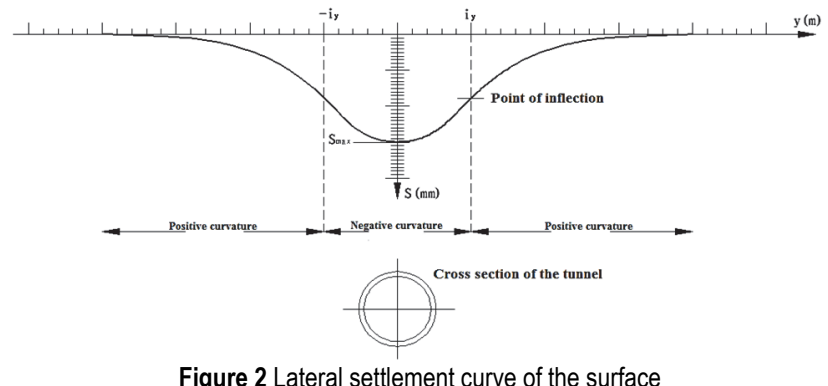

\subsection{Building Settlement}

In most practical projects, when assessing the effect of stratum settlement caused by tunnel excavation on a building, the deformation of the building is assumed the same as that of the natural ground. However, this assumption completely ignores the effect of structural stiffness. In fact, when considering the structural stiffness, the deformation curve of the building completely differs from that of the natural ground [7].

If formation loss rate $V_{l}$ is defined as the ratio between the area of the surface settlement tank and area of tunnel excavation $A$, the relationship between formation loss rate $V_{l}$ and maximum settlement $S_{\max }$ under the undrained condition can be obtained by integrating Eq.(1) as follows:

$$
S_{\max }=\frac{A \cdot V}{\sqrt{2 \pi} \cdot i_{y}}
$$

For the tunnel with a circular cross section, Eq. (2) can be expressed as follows:

$$
S_{\max }=0.313 V_{l} \cdot D^{2} / i_{y}
$$

where $D$ is the diameter of the circular tunnel, and the simple linear empirical relationship [8] between $i_{y}$ and buried depth $z_{0}$ of the tunnel axis can be shown as follows:

$$
i_{y}=K \cdot Z_{0}
$$

where $K$ refers to the width coefficient of the settling tank.

By integrating Eq. (3) and Eq. (4) into Eq. (1), a practical formula for estimating the lateral settlement of the natural ground (for circular tunnels) can be obtained as follows:

$$
S(y)=\frac{0.313 V_{l} \cdot D^{2}}{K \cdot Z_{0}} \exp \left[-\frac{y^{2}}{2\left(K Z_{0}\right)^{2}}\right]
$$

Considering the influence of structural stiffness of the building, width coefficient $K$ of the settling tank in Eq. (5) should be corrected, and therefore $K$ is replaced with $K^{\mathrm{M}}$ [9]:

$$
K^{\mathrm{M}}=\eta^{\mathrm{M}} \cdot K
$$

where $\eta^{\mathrm{M}}$ refers to the modification coefficient, which considers the structural stiffness. By taking $\eta^{\mathrm{M}}=0.7 M^{0.2}$ [10], where $M$ stands for the section shear stiffness of the structure (under the constriction effect of the tunnel, the deflection is mainly caused by vertical shear deformation of the building), the settlement curve of the building, considering the stiffness correction can be expressed as follows:

$$
S(y)=\frac{0.313 V_{l} \cdot D^{2}}{\eta^{\mathrm{M}} K \cdot Z_{0}} \exp \left[-\frac{y^{2}}{2\left(\eta^{\mathrm{M}} K Z_{0}\right)^{2}}\right]
$$

In addition, the calculation for the shear stiffness of the building's cross section can be expressed as follows:

$M=\sum_{i=1}^{n} \varsigma_{i} G_{i} A_{i}$

where $G_{i}, A_{i}$, , and $\varsigma_{i}$ represent the material shear modulus, sectional area, and stiffness reduction coefficient, which mainly considers the effects of various openings on the actual building, of the $i$-th structural member in the section, respectively. Further, $n$ represents the total components in the section, including the foundation plate, floor slab, beam, and wall.

\subsection{Calculation of Settlement Value of the Red House Hotel}

The shear stiffness of the transverse section of the Red House Hotel can be calculated according to Eq. (8). The results are shown in Tab. 1. Thus, the stiffness correction coefficient can be concluded to be $\eta^{\mathrm{M}}=1.71$. By integrating Eq. (7), the vertical settlement value of the Red House Hotel can be obtained by considering the stiffness modification. The burial depth (the distance from the ground to the center of the tunnel) was $18.5 \mathrm{~m}$, diameter of the tunnel was $6 \mathrm{~m}$, loss rate of the formation was $V_{l}=0.06$, and width coefficient $K=0.7$.

Table 1 Section stiffness of the Red House Hotel

\begin{tabular}{|c|c|c|c|c|c|c|c|}
\hline Member & $E / \mathrm{kN} / \mathrm{mm}^{2}$ & $v$ & $G / \mathrm{kN} / \mathrm{mm}^{2}$ & $A / \mathrm{m}^{2}$ & $\varsigma$ & $M_{i} \times 106 / \mathrm{kN}$ & Quantity \\
\hline Interior Wall & 2.0 & 0.15 & 0.869565 & 6.48 & 1.0 & 5.634783 \\
\hline Exterior Wall & 2.0 & 0.15 & 0.869565 & 9.72 & 1.0 & 8.452174 \\
\hline Floorslab & 10.0 & 0.2 & 4.166667 & 2.62 & 1.0 & 10.91667 \\
\hline Foundation & 3.0 & 0.15 & 1.304348 & 10.9 & 1.0 & 1 \\
\hline
\end{tabular}


The comparison chart between the vertical settlement curve of the Red House Hotel in consideration of the stiffness modification and settlement curve calculated by the conventional Peck formula is shown in Fig. 3.

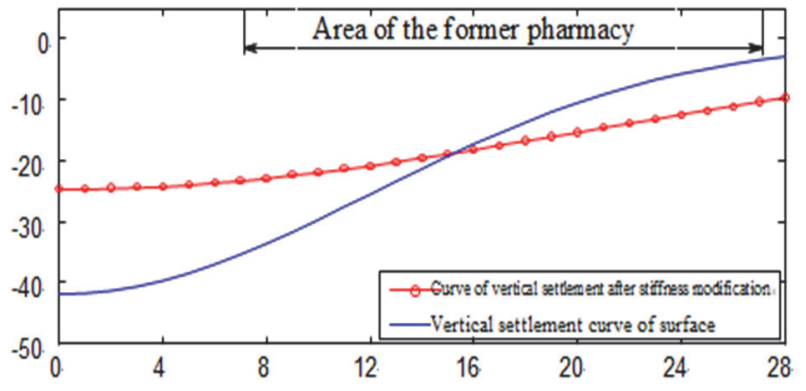

Figure 3 Vertical settlement curve calculated using the Peck formula of the building before and after the stiffness modification.

\section{FINITE ELEMENT ANALYSES \\ 4.1 Model Establishment}

According to the field measurement (materials, such as design drawings and geological surveys, are absent owing to the age of the building), the architectural plan of the Red House Hotel is depicted in Fig. 4. With a total length of $21.8 \mathrm{~m}$ and width of $20.1 \mathrm{~m}$, the building comprises one basement and three floors, among which the basement is $2.2 \mathrm{~m}$ high, the ground floor is $5.0 \mathrm{~m}$ high, and the second and third floors are $4.5 \mathrm{~m}$ high each. A three-dimensional model of the Red House Hotel was established through ANSYS (not considering the wooden roof), and the mesh model of the entire building is shown in Fig. 5.
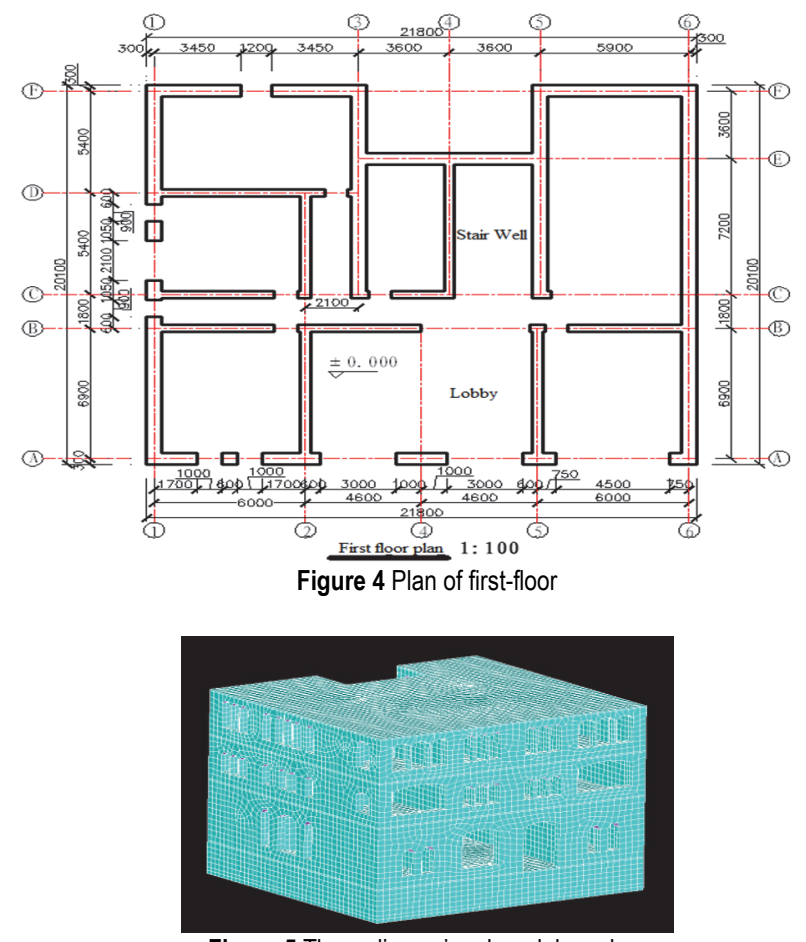

Figure 5 Three-dimensional model meshes

\subsection{Calculation and Analyses}

The vertical settlement value, which was calculated and modified, was considered as the uneven settlement condition of the building foundation. Then, a three- dimensional finite element model was used for calculation and analysis.

The equivalent stress nephogram of the model is shown in Fig. 6. The exterior wall facing the south of the building was determined to be more stressed than other exterior walls. This is because of the presence of numerous large holes in it. As a result, the wall will be most severely damaged by surface settlement. Therefore, this study was more targeted to analyze the stress on the wall to develop a pre-reinforcement plan before the subway construction.

Under stress, the window opening is considered as one of the weaknesses of the south-facing wall. The principal stress curve of the sills on all floors is plotted in Fig. 7. The tensile stress at the window sill of the hole was determined to increase with size of the opening, and the higher layer of the bottom floor was severely affected under stress. Moreover, the masonry at the sills on the first and second floors cracked $\left(f_{t m}=170 \mathrm{kPa}\right.$; the masonry is severely weathered as the building is over 100 - years old. According to the quality appraisal report of the building, the grade of the mortar strength is M2.5), while most of sills on the third floor remained un-cracked.

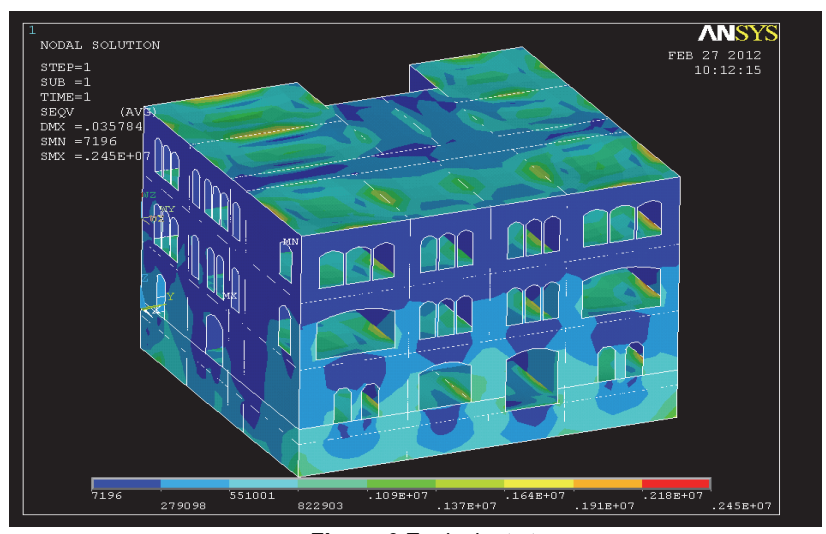

Figure 6 Equivalent stress

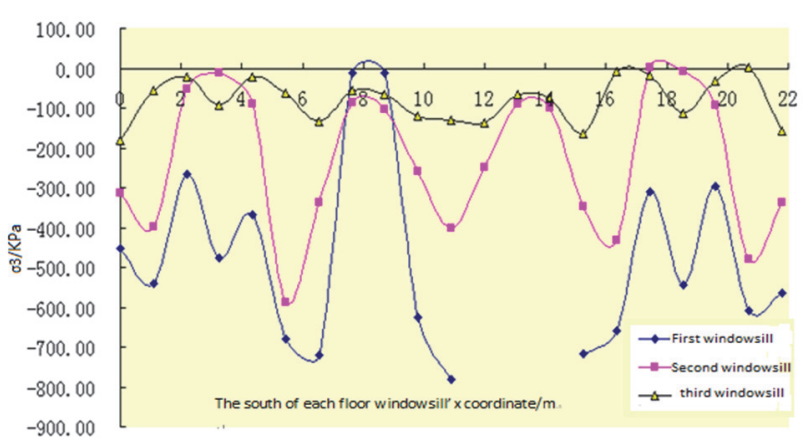

Figure 7 Principal stress curve of each floor's window sill at the south side

\section{REINFORCEMENTSCHEME}

Building No. 33 of the Red House Hotel located at Guangxi Road is a cultural relic protected at the national level and is currently in operation. Therefore, its construction and structural characteristics cannot be destroyed and the normal use of the hotel cannot be affected.

Based on the comprehensive stress analyses and the reasons mentioned earlier, the reinforcement scheme of the building can be designed from the aspects of foundation, ring beam, wall, and constructional column, and then the construction can be performed. 


\subsection{Foundation Reinforcement}

As shown in Fig. 8, in the process of reinforcing of the foundation, the section could be expanded by $200-300$ $\mathrm{mm}$ on both sides of the strip foundation of the wall, and $\mathrm{C} 25$ concrete could be poured. In addition, all sides of the brick column could be expanded by $200 \mathrm{~mm}$, and C25 concrete could be poured.

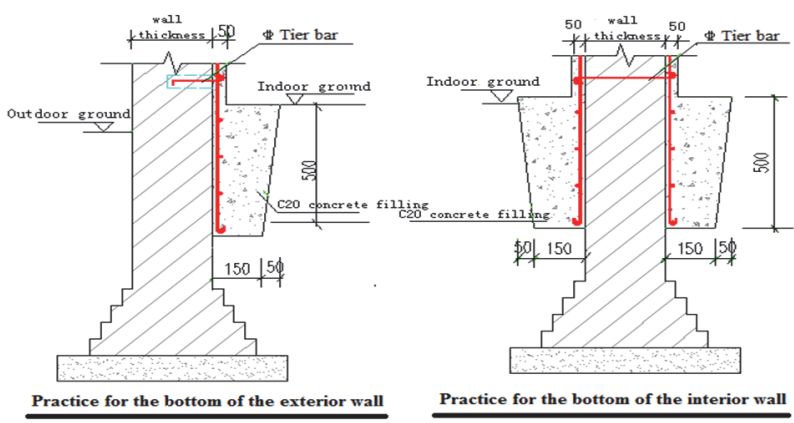

Figure 8 Reinforcement scheme

\subsection{Use of a Seismic Column And Closed Ring Beam}

As shown in Fig. 9, the building has a long history, while it is free of anti-seismic measures. Therefore, to protect its current condition, it is added with an antiseismic column and a ring beam and is fixed in combination with wall reinforcement.
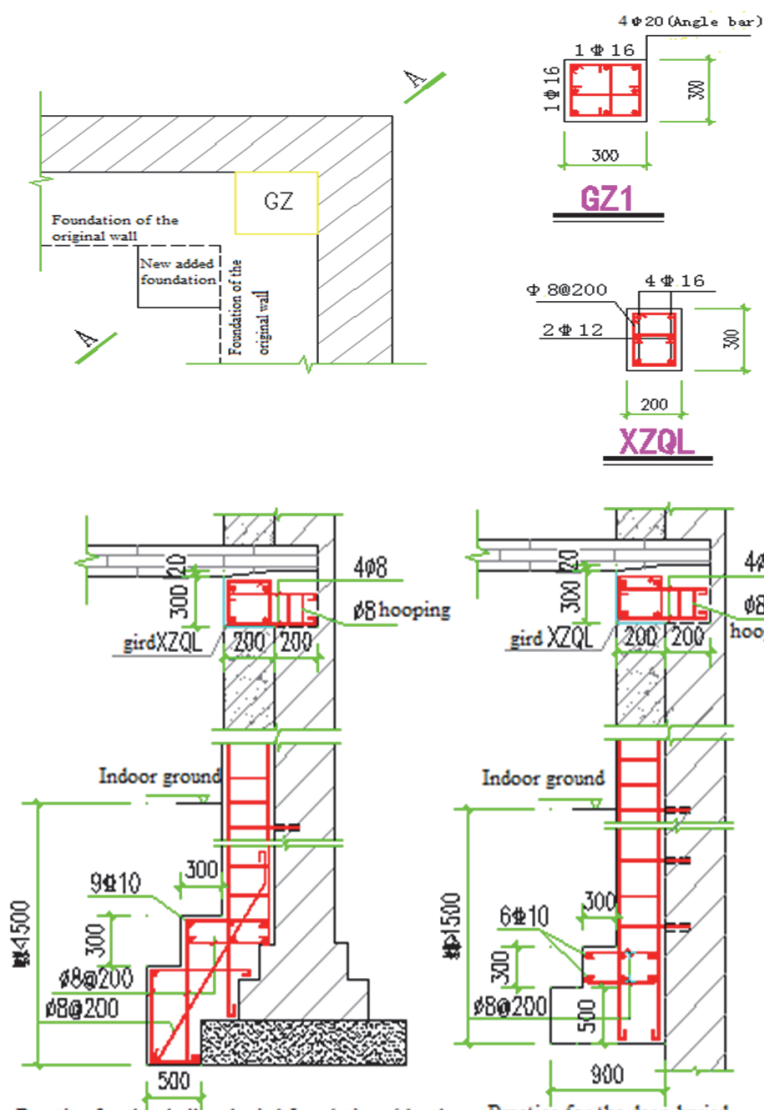

Practice for the shallow-buried foundation (depth of original foundation is less than 1500 )

$$
\text { A-A profile }
$$

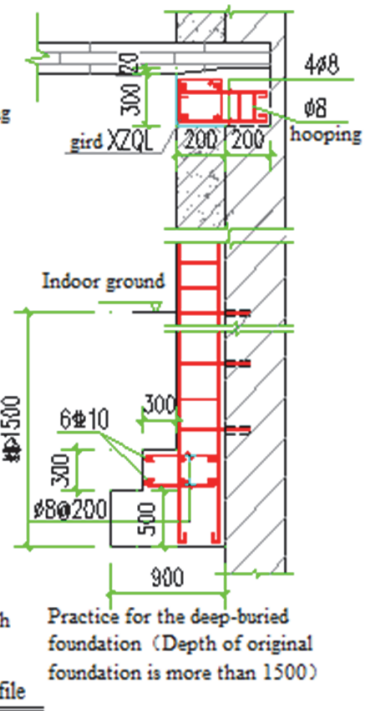

Detail of cement mortar with welded mesh reinforcement

Figure 9 Use of a seismic column and closed ring beam

\subsection{Use of Cement Mortar with Welded Mesh Reinforcement}

As shown in Fig. 10, to accurately integrate the seismic measures, apart from the anti-seismic column and ring beam, the M10 mesh reinforcement with a thickness of 50 $\mathrm{mm}$ will be arranged on the inner side of the exterior wall and on both sides of the interior wall to effectively ensure that the newly added seismic measures will play a protective role in the original structure.
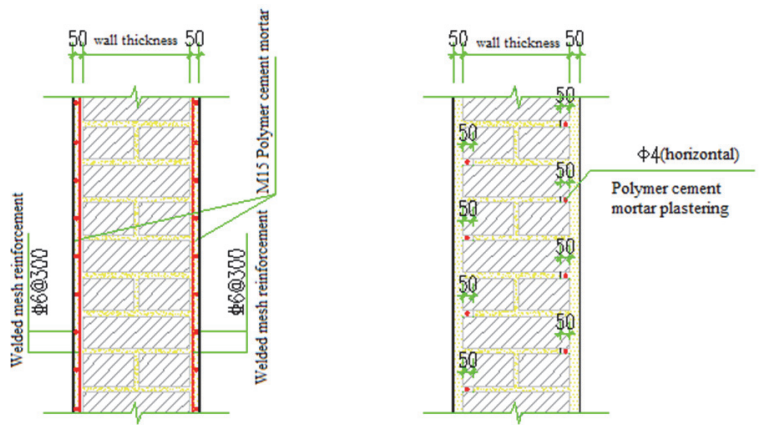

Diagram of cross section of reinforcement wall Diagram of brick joint reinforcement of the wall

Figure 10 Use of cement mortar with welded mesh reinforcement

\subsection{Setting the Arched Cement Mortar Reinforcement Layer}

As shown in Fig. 11 and Fig. 12, the entrances and windows of the south façade of the building are all arched. Owing to the age of the building, there is extensive weathering, and some of the wall mortar is obviously loose. Consequently, in addition to strengthening the existing brick joints, a curved reinforced concrete mortar surface layer and a vertical brick column reinforcement surface layer were added to strengthen the top of the hole, and the bearing capacity of the middle brick column in the window opening was significantly enhanced.

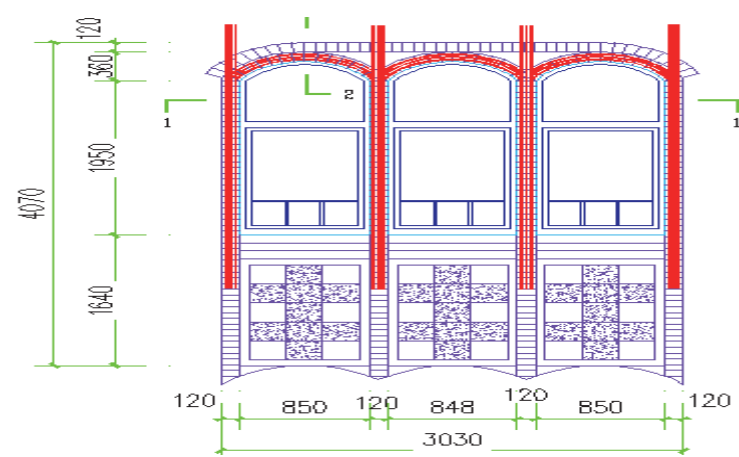

Figure 11 Doors and windows of wall facing south
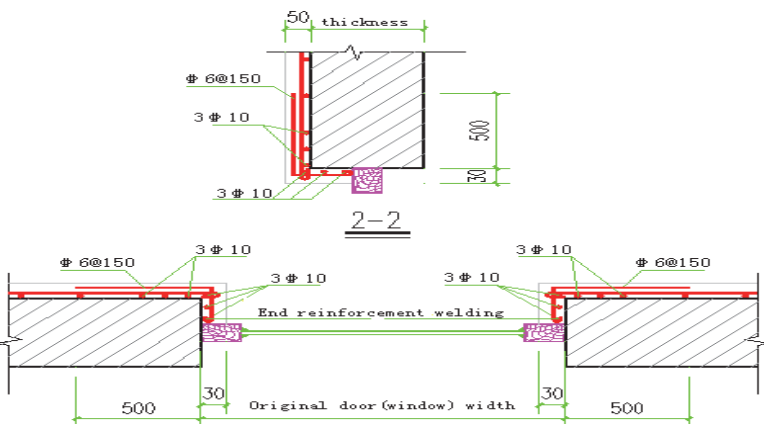

Figure 12 Top of the opening 


\section{CONCLUSION}

This paper analyzed the relationship between surface settlement and building settlement under the influence of subway excavation, and modified the Peck formula by considering the building stiffness. The predicted value of the settlement after modification was applied to the Red House Hotel (a cultural relic that is under national protection and is specified as the research object) and ANSYS-based finite element analyses were conducted. Furthermore, the analysis results could provide a certain theoretical basis for the design and implementation of the reinforcement scheme of actual buildings as well as offer guidance for the study of the protection of buildings near the Qingdao subway in the process of tunnel excavation.

\section{Acknowledgements}

We would like to thank Editage (www.editage.cn) for English language editing.

\section{REFERENCES}

[1] Hudson, J. A. (1994). Comprehensive rock engineering: principles,practice \&; projects, volume4: excavation, support and monitoring. Engineering Geology, 37(94). 314315. https://doi.org/10.1016/0013-7952(94)90070-1

[2] Franzius, J. N. (2003). Mechanics of tunnelling-induced ground movement, their progressive effects on buildings and mitigation (Ph. D. Thesis). London: Imperial College. https://doi.org/10.3208/sandf.44.25

[3] Lei, Y. S. (2010). Research on protective measures of City $\mathrm{W}$ all and Bell Tower due to underneath crossing Xi'an Metro Line No. 2. Rock and Soil Mechanics, 31(1), 223236.

[4] Vorster, T. E., Klar, A., Soga, K., et al. (2005). Estimating the effects of tunneling on existing pipelines. Journal of Geotechnical and Geoenvironmental Engineering, 131(11), 1399-1410. https://doi.org/10.1061/(ASCE)1090-0241(2005)131:11(1399)

[5] Xu, L. H., Ai, X. Y., Yu, J. L., et al. (2010). Anallysis of impact of tunnel construction on Masonry buildings in Xiamen airport road. Chinese Journal of Rock Mechanics and Engineering, 29(3), 583-592.

[6] Peck, R. B. (1969). Deep excavations and tunnelling in soft ground. Proceedings of the 7th International Conference on Soil Mechanics and Foundation Engineering, Mexico City, 225-290.

[7] Frischmann, W. W., Hellings, J. E. Gittoes, G., \& Snowden, C. (1994). Protection of the mansion house against damage caused by ground movements due to the docklands light railway extension. Proc.InstnCivEngrs, Geotechnical Engineering, 107(2), 65-76. https://doi.org/10.1680/igeng.1994.26374

[8] O"Reilly, M. P. \& New, B. M. (1982). 831153 Settlement above tunnels in the United Kingdom-their magnitude and prediction : In: Tunneling 82, Proceedings of the 3rd International Symposium, Brighton, P173-181. Publ London: IMM, 1982. International Journal of Rock Mechanics \& Mining Sciences \& Geomechanics Abstracts, 20(1), 0-0. https://doi.org/10.1016/0148-9062(83)91768-0

[9] Dimmock, P. \& Mair, R. (2008). Effect of building stiffness on tunnelling-induced ground movement. Tunnelling \& Underground Space Technology Incorporating Trenchless Technology Research. 23(4), 438-450. https://doi.org/10.1016/j.tust.2007.08.001
[10] Han, X. (2006). The analysis and prediction of tunnelinginduced building deformations (Ph. D. Thesis). Xi'an: Xi'an University of Technology.

[11] Leitner, A., Herzfeld, T., Nebois, C., et al. (2017). The new line crossing $\mathrm{U} 2 / \mathrm{U} 5$ of the Vienna subway: dasneuelinienkreuz U2/U5 der Wiener U-Bahn. Geomechanik Und Tunnelbau, 10(4), 395-405. https://doi.org/10.1002/geot.201700016

[12] The Professional Standards Compilation Group of People's Republic of China. (2000). JGJ 116-2009 Technical specification for seismic strengthening of buildings (S). Beijing : China Architecture and Building Press.

[13] Huang, Z. B. (1994). Testing study of tiebars in brick wallstrengthened with bar-mat reinforced cement mortar. Journal of Experimental Mechanics, 9(4), 383-389.

[14] Xu, Q. F., Jiang, H. C., Zhu, L., et al. (2009). Experimental study of old brick masonry wall strengthened with steelmeshed cement mortar. China Civil Engineering Journal, 42(4), 77-83.

[15] Group of People's Republic of China. (2003). CECS 146:2003 Technical specification for strengthening concrete structures with carbon fiber reinforced polymer laminate. Beijing : China Plan Press.

[16] Lin, L. \& Ye, L. P. Experimental investigation on masonry wall strengthened with FRP. Building Structure, 35(3), 21 27.

\section{Contact information}

\section{Shaodong YUAN}

Qingdao University of Technology,

School of Civil Engineering, Qingdao University of Technology,

Qingdao266033, China

E-mail:13808957683@163.com

\section{Guangming YU}

Qingdao University of Technology,

School of Civil Engineering, Qingdao University of Technology,

Qingdao266033, China

E-mail:861692371@qq.com

\section{Liang LI}

(Corresponding author)

Qingdao University of Technology,

School of Civil Engineering, Qingdao University of Technology,

Qingdao266033, China

E-mail: liliang@qut.edu.cn 